03

\title{
Осаждение алмазных структур из взаимодействующих газовых струй
}

\author{
(ㄱ А.А. Емельянов, А.К. Ребров, И.Б. Юдин
}

Институт теплофизики СО РАН

630092 Новосибирск, Россия

e-mail: yudinib@gmail.com

(Поступило в Редакцию 5 апреля 2016 г.)

Представлены результаты экспериментов газоструйного синтеза алмаза из потоков метана и водорода при различных условиях смешения. Предложен оригинальный способ раздельной подачи газовых струй, позволяющий достичь высокой скорости роста алмазной фазы. Синтез алмазных структур при газоструйном осаждении исследовался при раздельной подаче двух потоков - водорода и смеси водорода с метаном в двух вариантах: с боковой подачей метаносодержащей смеси и осесимметричной подачей. Эксперименты проводились при условиях: температура поверхности, активирующей водород, $2400 \mathrm{~K}$, температура подложки от 900 до $1300 \mathrm{~K}$, давление в камере осаждения $2 \cdot 10^{2}$ Ра, потоки газовых смесей по водороду $1500 \mathrm{ncm} / \mathrm{min}_{\text {, }}$ концентрация $\mathrm{CH}_{4}$ в $\mathrm{H}_{2}$ от 0.1 до $0.7 \%$, расстояние подложки от реактора $10 \mathrm{~mm}$. В случае раздельной боковой подачи метаносодержащего газа и водорода достигнута скорость осаждения $20 \mu \mathrm{m} / \mathrm{h}$, в случае осесимметричной раздельной подачи газов выращен монокристалл весом $0.6 \mathrm{mg}$, что соответствует скорости осаждения примерно $200 \mu \mathrm{m} / \mathrm{h}$.

Одно из первых исследований химической кристаллизации алмаза при раздельной подаче взаимодействующих потоков проведено в начале 70-х годов Б.В. Спицыным [1]. Из потоков, активированных $\mathrm{H}_{2}$ и $\mathrm{CH}_{4}$, на кристалле алмазного зародыша была достигнута скорость роста $1 \mu \mathrm{m} / \mathrm{h}$. Невысокая скорость роста объясняется, по-видимому, недостаточно высокой температурой вольфрамовой трубки и метанового капилляра и неизбежным влиянием науглероживания (карбидизации) отравлением каталитических свойств вольфрамовой поверхности трубки. Сведения о влиянии науглероживания поверхности на синтез алмазного покрытия приведены в работе [2].

В случае термической активации на проволочках (HWCVD) активированная смесь водорода и углеводородов образуется при однократных столкновениях молекул исходного газа с горячими поверхностями нагретых проволочек. Когда активация потока исходных газов происходит на протяженной высокотемпературной поверхности, многократные столкновения приводят к глубокой диссоциации водорода и разложению метана. Эта концепция реализована в работах [3-6].

Для газоструйного осаждения алмазных структур был разработан реактор с высокой степенью диссоциации потока водорода, важнейшими элементами которого являются вольфрамовая трубка 1 диаметром $10 \mathrm{~mm}$, длиной $25 \mathrm{~mm}$ и вольфрамовая спираль с толщиной проволоки $1 \mathrm{~mm}$, диаметром канала в ней $3 \mathrm{~mm}$. Расстояние между выходом спирали и молибденовой подложкой 3 равно $10 \mathrm{~mm}$. Температура молибденовой подложки регулируется с помощью дополнительного нагревателя 4. Температуры трубки 1 и подложки 3 измеряются термопарами. Эксперименты с совместной подачей газов проведены для изучения влияния науглероживания поверхности активатора на рост алмаза (рис. 1). Температура экрана $1-2400 \mathrm{~K}$, температура молибденовой подложки -
$1300 \mathrm{~K}$. Осаждение вместе с начальным периодом нуклеации длилось $4 \mathrm{~h}$ при давлении в вакуумной камере $2 \cdot 10^{3} \mathrm{~Pa}$, расходе водорода 1500 и метана $10 \mathrm{ncm}^{3} / \mathrm{min}$. Смесь подавалась в трубку 1 через сопло на расстоянии $25 \mathrm{~mm}$ от выхода. При низком давлении и очень высокой температуре способ подачи газа в трубку не имеет значения из-за высокой скорости распространения тепловых возмущений. На рис. 2 показана морфология полученных кристаллов с растрового электронного микроскопа Karl Zeiss LEO-420. Эти кристаллы осаждены с чистой (без науглероживания) вольфрамовой спиралью и трубкой. Скорость роста была $5 \mu \mathrm{m} / \mathrm{h}$. После экспериментов общей длительностью $12 \mathrm{~h}$ в результате длительной подачи смеси $\mathrm{H}_{2}+\mathrm{CH}_{4}$ вследствие науглероживания спирали и трубки скорость роста алмаза уменьшилась до $1 \mu \mathrm{m} / \mathrm{h}$.

Результаты синтеза алмаза из взаимодействующих струй были получены при подаче смеси метана и водорода через внешний капилляр в активированную струю водорода (рис. 1). Вольфрамовый капилляр 5 с внутренним диаметром 3, 6 mm для подачи смеси метана

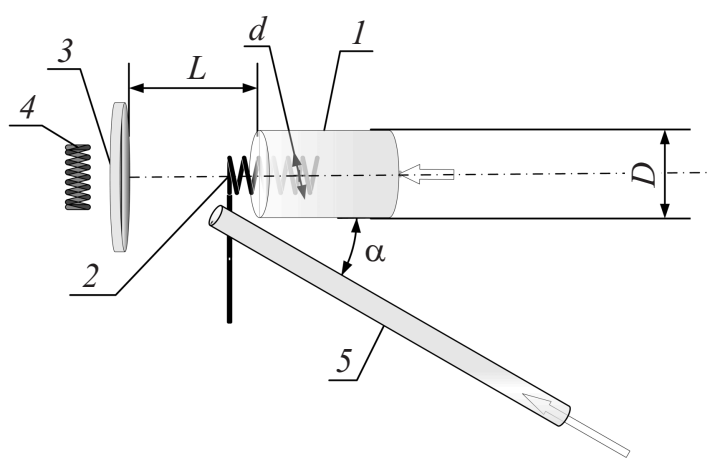

Рис. 1. Схема совместной и раздельной подачи активных газов. 1 - трубка активатора, 2 - вольфрамовая спираль, 3 - подложка, 4 - нагреватель, 5 - вольфрамовый капилляр. 


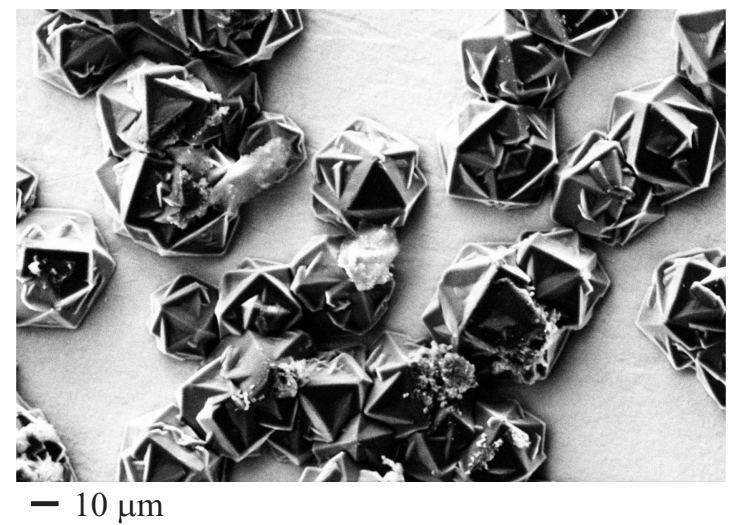

Рис. 2. Осажденные кристаллы алмаза при раздельной подаче $\mathrm{H}_{2}$ и смеси $\mathrm{H}_{2}+0.4 \% \mathrm{CH}_{4}$.

и водорода расположен под углом $30-45^{\circ}$ к оси трубки 1 так, что точка пересечения осей капилляра и трубки попадает на центр подложки. Капилляр нагревается излучением от спирали и трубки 1 , теплопроводностью от горячего окружающего газа. Условия эксперимента: давление в камере $2 \cdot 10^{3} \mathrm{~Pa}$, температура вольфрамовой трубки, подложки и вольфрамового капилляра 2400 , 1250 и около $1700 \mathrm{~K}$ соответственно, расход водорода через трубку $1-1500 \mathrm{ncm}^{3} / \mathrm{min}$; через капилляр 5 подавалась смесь $1500 \mathrm{ncm}^{3} / \mathrm{min}_{2}$ с концентрацией метана от 0.126 до $0.52 \%$; продолжительность осаждения 4 h. Трубка 1 была выполнена из вольфрамовой фольги толщиной $0.05 \mathrm{~mm}$, свернутой в трубку в два слоя. Ее температура измерялась вольфрам-рениевой термопарой, вставленной между слоями. Активация водорода происходила на поверхности вольфрамовой трубки и спирали.

На рис. 2 морфология осажденных кристаллов представлена для экспериментов с примесью $\mathrm{CH}_{4} \quad 0.4 \%$. У изолированных кристаллов есть выделенная плоскость с ориентацией (111). Скорость роста увеличивалась с увеличением концентрации $\mathrm{CH}_{4}: 1.5,15,20 \mu \mathrm{m} / \mathrm{h}$ для концентраций метана $0.26,0.4,0.53 \%$ в водородном потоке $1500 \mathrm{ncm}^{3} / \mathrm{min}$. Кристаллы, полученные в случае подачи метана через капилляр $3 \mathrm{~mm}$, имеют скорость роста примерно в 3 раза выше, чем при использовании капилляра $6 \mathrm{~mm}$, при этом получаемое углеродное покрытие имеет более равномерное распределение на подложке.

На рис. 3 представлен спектр комбинационного рассеяния света углеродного покрытия, полученного при осаждении в течение $3 \mathrm{~h}$ при подаче метана через капилляр $3 \mathrm{~mm}$. Скорость роста пленки в этом случае была получена около $5 \mu \mathrm{m} / \mathrm{h}$.

Спектры комбинационного рассеяния получены на приборе Т64000 Horiba Jobin Yvone при использовании лазера с длиной волны $514.5 \mathrm{~nm}$. Наличие $G$-пика в районе $1600 \mathrm{~cm}^{-3}$ свидетельствует о значительном содержании $s p^{2}$-гибридизации в конфигурации углеродной структуры. Из рис. 4 следует, что для выбранных параметров осаждения с увеличением концентрации метана происходит увеличение скорости роста кристаллов алмаза. Наибольшая скорость достигается при концентрациях $0.45-0.55 \%$ метана. При малых концентрациях $(0.1-0.25 \%)$ скорость остается малой из-за недостаточного количества углерода. Пленки, полученные при концентрациях метана $0.6 \%$ и более, имеют на поверхности большие осаждения графита. Это обстоятельство свидетельствует о недостаточном количестве атомарного водорода. В зависимости от локальных условий взаимодействия струй с подложкой наблюдалась различная морфология осаждения: от плотной пленки до изолированных кристаллов в форме икосаэдров. При внешней подаче метана под углом к потоку водорода трудно получить равномерное покрытие на подложке. Результат же экспериментов можно считать полезным, указывающим на возможность получения высоких

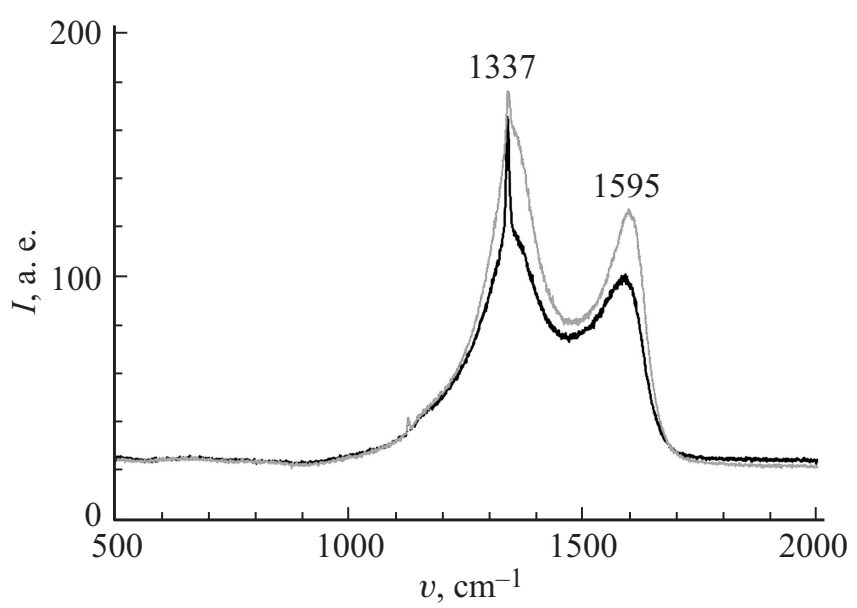

Рис. 3. Спектр комбинационного рассеяния света углеродного покрытия, полученного при внешней подаче смеси $\mathrm{H}_{2}+0.3 \% \mathrm{CH}_{4}$ (кривые относятся к разным точкам на подложке).

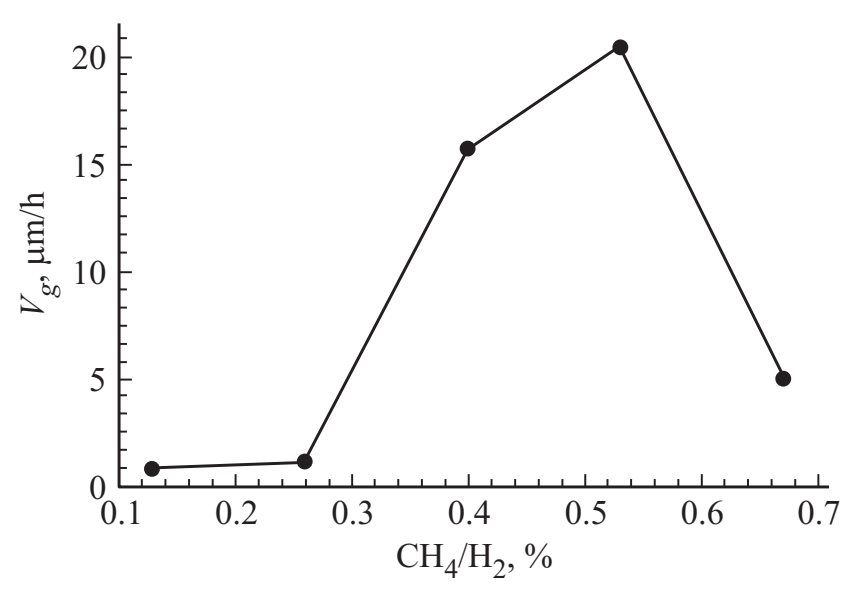

Рис. 4. Скорость роста изолированных кристаллов алмаза при раздельной подаче $\mathrm{H}_{2}$ и смеси $\mathrm{H}_{2}+0.4 \% \mathrm{CH}_{4}$ (подача метана через капилляр $3 \mathrm{~mm}$ ). 


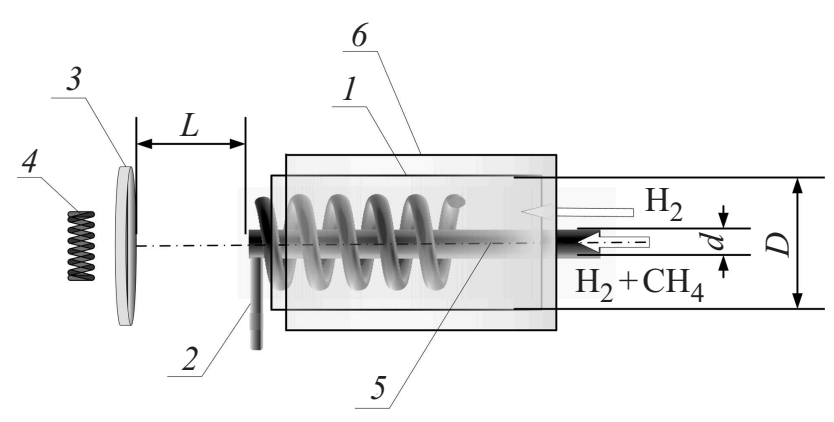

Рис. 5. Двухканальный активатор со спиралью нагрева в водородном канале. 1 - трубка активатора, 2 - вольфрамовая спираль, 3 - подложка, 4 - нагреватель, 5 - вольфрамовый капилляр, 6 - тепловой экран.

скоростей осаждения $(20 \mu \mathrm{m} / \mathrm{h})$. Важными факторами, определяющими смешение взаимодействующих потоков, являются отношение молекулярных масс и отношение скоростей [7].

В экспериментах с использованием соосного 2-канального активатора со спиралью нагрева в кольцевом водородном канале (рис. 5) смесь метана и водорода подается через вольфрамовый капилляр 5 диаметром $2 \mathrm{~mm}$, который расположен на осевой линии внутри вольфрамовой спирали 2 с внутренним диаметром $7 \mathrm{~mm}$. Спираль имеет 6 витков с шагом намотки $3 \mathrm{~mm}$ и выполнена из проволоки диаметром $1 \mathrm{~mm}$. Спираль располагается соосно внутри трубки 1 диаметром $13 \mathrm{~mm}$. Трубка была выполнена из вольфрамовой фольги толщиной $0.05 \mathrm{~mm}$, свернутой в два слоя. Она окружена цилиндрическим экраном 6 диаметром $18 \mathrm{~mm}$ из молибденовой фольги толщиной $0.2 \mathrm{~mm}$, свернутой в два слоя.

Температура стенок капилляра 5 и трубки активатоpa 1 измерялась вольфрам-рениевой термопарой, вставленной между слоями. Эксперименты были выполнены при условиях: давление в камере $2 \cdot 10^{3} \mathrm{~Pa}$; температура вольфрамовой трубки, подложки и вольфрамового капилляра 2400,1250 и около $2400 \mathrm{~K}$ соответственно; расход водорода через кольцевой канал трубки 1 $1500 \mathrm{ncm}^{3} / \mathrm{min}$; через капилляр 5 подавался поток смеси: $500-1500 \mathrm{ncm}^{3} / \mathrm{min}_{2}+0.15-0.5 \% \mathrm{CH}_{4}$; продолжительность осаждения $3 \mathrm{~h}$.

Основным отличием этого активатора являются особые газодинамические условия осаждения. Поперечное сечение кольцевого канала примерно в 30 раз больше сечения капилляра. При одинаковых расходах водорода в каналах и примерно одинаковой температуре торможения удельные импульсы потоков у среза капилляра отличаются примерно в 900 раз. Это означает, что изначально сверхзвуковой поток из капилляра тормозится практически в покоящемся газе, что создает благоприятные условия для смешения. Еще одной особенностью активатора по сравнению с другими (ранее испытанными) является увеличенная поверхность контакта водорода с активирующей поверхностью, что согласуется с данными работы [8].

В эксперименте с описанным активатором при использовании смеси $\mathrm{H}_{2}+0.17 \% \mathrm{CH}_{4}$ выращен монокристалл

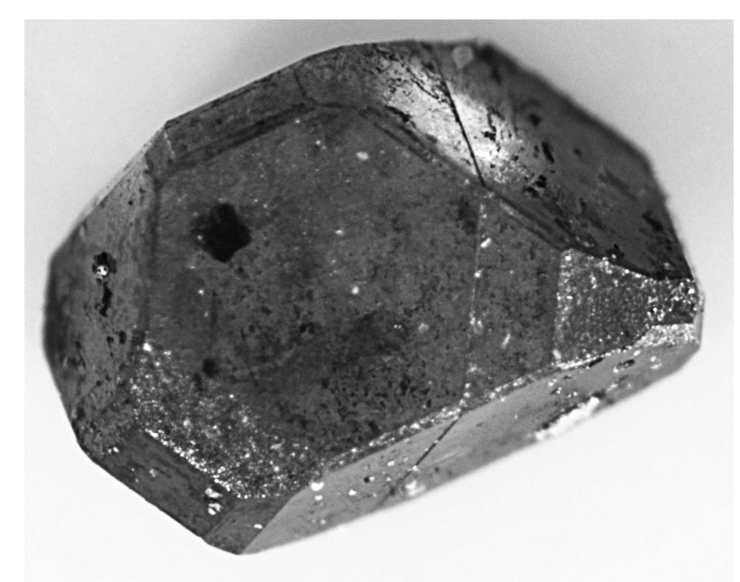

Рис. 6. Фотография синтезированного кристалла алмаза весом $0.6 \mathrm{mg}$ (габаритные размеры кристалла $1.8 \times 1.8 \times 0.5 \mathrm{~mm}$ ).

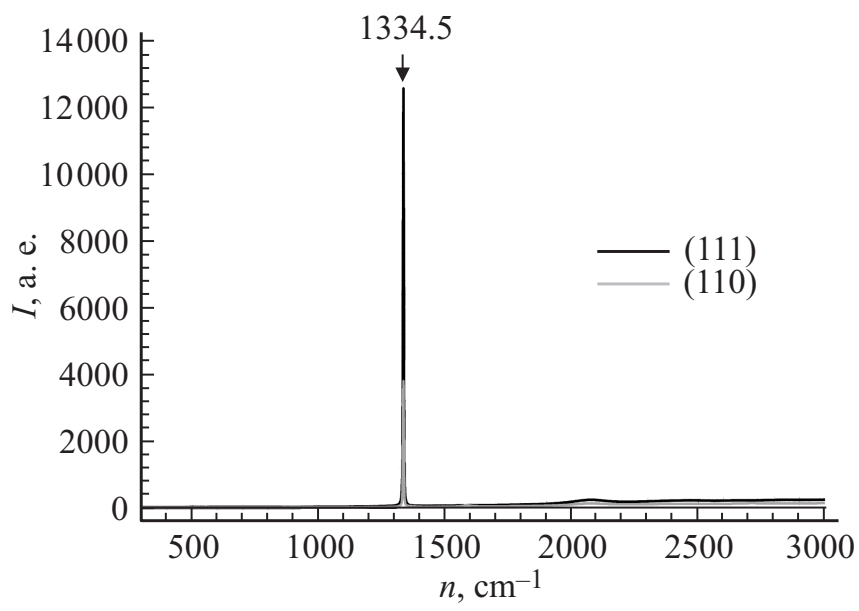

Рис. 7. Спектр комбинационного рассеяния света алмазного кристалла.

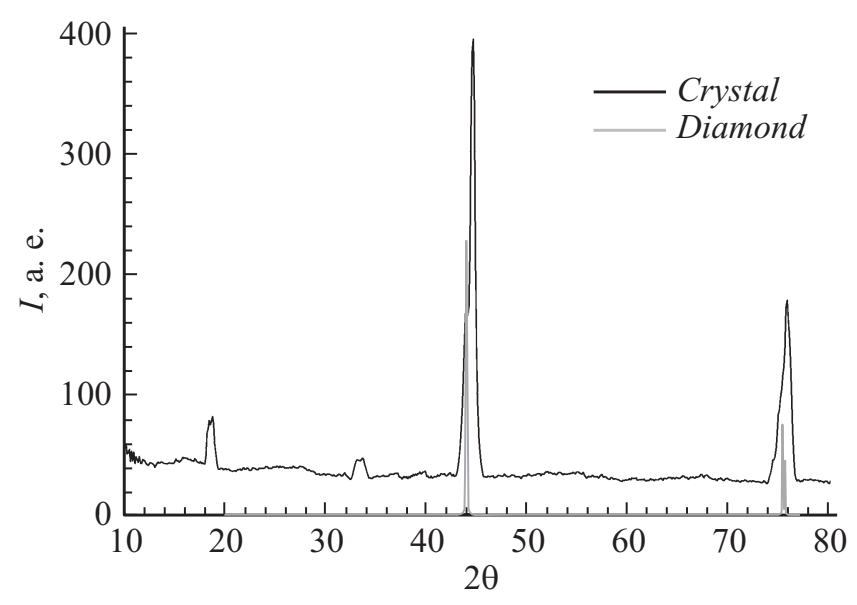

Рис. 8. Рентгенограмма кристалла алмаза и модельный алмазный спектр. 
весом $0.6 \mathrm{mg}$ (рис. 6). На рис. 7 представлен спектр комбинационного рассеяния света этого кристалла, соответствующий алмазу высокого качества. Обе грани (111) и (110) имеют отклик $1334.5 \mathrm{~cm}^{-1}$.

На рис. 8 представлена дифрактограмма монокристалла алмаза, полученная на приборе Bruker DUO (Сu $K_{\alpha}$-излучение, схема Дебая-Шеррера).

Основные пики по положению соответствуют алмазу. Мультиплетный вид пиков указывает на возможную вариацию параметра элементарной кубической ячейки. Пик для $33^{\circ}$ свидетельствует о наличии неидентифицированной примеси.

Представленные результаты экспериментов синтеза алмазных структур с осесимметричной подачей дают основания для дальнейшего развития газоструйного осаждения. Его преимуществами являются отсутствие науглероживания рабочих поверхностей активатора, высокая скорость роста алмазной фазы, широкий диапазон изменения параметров. Избавлен он и от основного недостатка активатора с боковой подачей - непредсказуемой неоднородности получаемых покрытий, что затрудняет воспроизводство экспериментов.

Работа выполнена при поддержке грантов РФФИ 14-08-01949 и 14-08-00839.

\section{Список литературы}

[1] Spitsin B.V. Handbook of Crystal Growth. Amsterdam, Elsevier, 1994. Vol. 3. Chap. 10. P. 401.

[2] Okoli S., Haubner R., Lux B. // Surface and Coatings Technology. 1991. Vol. 47. N 1-3. P. 585-599.

[3] Emelyanov A., Rebrov A., Yudin I. // Phys. Stat. Solidi (a). 2014. Vol. 211. N 10. P. 2279-2283.

[4] Rebrov A., Emelyanov A., Kosolobov S., Yudin I. // Phys. St. Sol. C. 2015. Vol. 12. N 7. P. 931-933.

[5] Емельянов А.А., Ребров А.К., Юдин И.Б. // Прикладная механика и техническая физика. 2014. Т. 55. № 2.

[6] Rebrov A.K., Emelyanov A.A., Yudin I.B. // Thin Solid Films. 2015. Vol. 575. P. 113-116.

[7] Славнов В.М. // Ученые записки ЦАГИ. Т. 1. 1970. № 3. P. $106-108$.

[8] Rebrov A., Yudin I. // Phys. Stat. Sol. C. Vol. 12. N 7. P. 886-890. 